\title{
Natural radioactivity levels and radiation hazards for gypsum materials used in Egypt
}

\author{
Ahmed Hassan Korna ${ }^{1^{*}}$, Soad Saad Fares ${ }^{2}$, Magda Abd El-Rahman $^{2}$ \\ ${ }^{1}$ Department of Physics, Faculty of Science, Al Baha University, Al Bahah, KSA; *Corresponding Author: Korna2@yahoo.com \\ ${ }^{2}$ Department of Radiation Physics, National Center of Radiation Research and Technology NCRRT, Atomic Energy Authority, Cairo, \\ Egypt
}

Received 20 September 2013; revised 20 October 2013; accepted 27 October 2013

Copyright (C) 2014 Ahmed Hassan Korna et al. This is an open access article distributed under the Creative Commons Attribution License, which permits unrestricted use, distribution, and reproduction in any medium, provided the original work is properly cited. In accordance of the Creative Commons Attribution License all Copyrights (C) 2014 are reserved for SCIRP and the owner of the intellectual property Ahmed Hassan Korna et al. All Copyright (C 2014 are guarded by law and by SCIRP as a guardian.

\section{ABSTRACT}

Radionuclides naturally occurring in building materials may significantly contribute to the annual doses to the public. For instance, familiar building materials such as the concrete and gypsum board have been reported to produce a dose of about $0.04 \mathrm{mSv}$ per year for a typical person (NCRP 1987c). External as well as internal exposures are two pathways of radiation dose imparted to human beings from the building materials. As information on the radioactivity of such materials is lacking, the study of gypsum materials used in Egypt was carried out in order to estimate the annual dose to the Egyptian population due to natural radionuclides in building materials. During the study, 18 samples of commonly used gypsum raw materials were collected and measured. The activity concentrations were determined by gamma ray spectrometry. Their mean values were in the ranges of $499.29 \pm 11.53 \mathrm{~Bq} \cdot \mathrm{kg}^{-1}$ for ${ }^{40} \mathrm{~K}, 91.97 \pm$ $2.61 \mathrm{~Bq} \cdot \mathrm{kg}^{-1}$ for ${ }^{226} \mathrm{Ra}, 37.62 \pm 1.67 \mathrm{~Bq} \cdot \mathrm{kg}^{-1}$ for ${ }^{238} \mathrm{U}$ and $42.27 \pm 2.22 \mathrm{~Bq} \cdot \mathrm{kg}^{-1}$ for ${ }^{232} \mathrm{Th}$. The activity indexed ly for 18, different gypsum samples varied from $0.31 \pm 0.03$ to $2.3 \pm 0.19$ and the radium equivalent activity $\left(R_{\text {aeq }}\right)$, from $38.81 \pm$ 1.68 to $324.7 \pm 9.42$. These values are lower than the limit of $370 \mathrm{~Bq} \cdot \mathrm{kg}^{-1}$ adopted by the Organization for Economic Cooperation and Development (OECD). The average indoor annual effective gamma dose rate (DE) in (mSv/y) for the people, caused by the building materials of dwellings, was assessed for most commonly gypsum materials. It was estimated to be in the range from $0.10 \pm 0.003 \mathrm{mSv} / \mathrm{y}$ to $0.74 \pm 0.08$
mSvly. The internal and external hazard indices $\left(H_{i n}, H_{e x}\right)$ and the absorbed dose rate in air $D$ in each sample were evaluated to assess the radiation hazard for people living in dwelling made of the studied materials. The absorbed dose rate of indoor air in samples G1, G2, G11, G17 and G18 is less than the international recommended value which is $55 \mathrm{nGyh}^{-1}$. While the absorbed dose rate for samples $\mathbf{G 3}, \mathbf{G 4}, \mathbf{G 5}, \mathbf{G 6}, \mathbf{G 7}, \mathbf{G 8}, \mathbf{G 9}$, G10, G12, G13, G14, G15 and G16 is higher than $55 \mathrm{nGyh}^{-1}$, these samples are not acceptable for use as building materials.

\section{KEYWORDS}

Gypsum; Gamma Spectrometer; Hazard Indices; NORM; Building Materials

\section{INTRODUCTION}

Gypsum is a naturally occurring mineral made up of calcium sulfate and water $\left(\mathrm{CaSO}_{4} \cdot 2 \mathrm{H}_{2} \mathrm{O}\right)$ which is sometimes called hydrous calcium sulfate. It is the mineral calcium sulfate with two water molecules attached. By weight, it is $79 \%$ calcium sulfate and $21 \%$ water. Gypsum has $23 \%$ calcium and $18 \%$ sulfur, and its solubility is 150 times than that of limestone, so it is a natural source of plant nutrients. Gypsum naturally occurs in sedimentary deposits from ancient sea beds. Gypsum is mined and made into many products like drywall used in construction, agriculture and industry. It is also a byproduct of many industrial processes. Gypsum is also used as a generic name for many types of sheet products made of a non-combustible core with a paper surfacing that adds strength. These include drywall, ceiling tiles, partitions, etc., whose strength is directly related to its 
thickness and a few trace materials. Gypsum has been known for centuries as a building material. The earliest known use of gypsum as a building material was in Anatolia around 6000 B.C.

Gypsum has been found in the interiors of the great pyramids in Egypt, which were erected in about 3700 B.C. Gypsum is found in every continent in the world and is one of the most widely used minerals. Synthetic gypsum is generated as a byproduct in flue-gas desulfurization (FGD) systems used to reduce sulfur dioxide emissions from coal-fired electric power plants. These (FGD) systems not only keep the air clean, but also provide a sustainable, ecologically sound source of very pure gypsum. Synthetic gypsum is also generated by various other acid-neutralizing processes [1,2]. Worldwide gypsum is used in Portland cement, which is used in concrete for bridges, buildings, highways, and many other structures that are parts of our daily life. Gypsum is also extensively used as a soil conditioner on large tracts of land in suburban areas and in agricultural regions. There are several types of naturally occurring gypsum, and many industrial processes also produce gypsum as a by-product of their systems such as phosphoric acid and citric acid manufacture. Mined gypsum is found in various locations around the world. Chemically raw mined gypsum is primarily calcium sulfate hydrated with water molecules in its chemical structure. Other materials and chemicals in mined gypsum may be small amounts of sand or clay particles and a few trace elements. The trace elements may be boron, iron, arsenic and lead and with different concentration. Primarily mined gypsum is very safe to use and is a great amendment for many soils.

Finely ground gypsum rock was used in agriculture and other industries to neutralize sodic soils, to improve soil permeability, to add nutrients, to stabilize slopes, and to provide catalytic support for maximum fertilizer benefits. Small amounts of high-purity gypsum also were used in a wide range of industrial operations, including the production of foods, glass, paper, and pharmaceuticals. Amongst the activities identified in the European, Basic Safety Standards Directives (BSS), which the standard sets the concern "with the production of residues which contain naturally occurring radionuclides causing a significant increase with the exposure of members from the public...". Such materials may include coal ash from power stations, by-product gypsum and certain slugs, which are produced in large volumes and, which may potentially be used as building materials [3]. Scientific investigations have long concluded that prolonged exposure to low-dose radiation can induce deleterious effects in humans; it was found necessary to establish levels of radioactivity in this product and associated radiation risk [4]. The aim of this paper is to in- vestigate the radioactivity of gypsum and establish radiation levels in materials suspected to have natural radioactivity radiation risk in Egypt.

\section{MATERIALS AND METHOD}

18 gypsum samples were collected from natural and manufactured building materials used in Egypt. The gypsum samples were dried, pulverized and packed in $200 \mathrm{~g}$ by mass in the cylindrical plastic containers of radius 3 inch and height 3.5 inch, which sits on the ( 3 inch $\times 3$ inches) high purity germanium (HPGe) detector with high geometry. The containers are sealed for about four weeks to ensure radioactive equilibrium between the parent radionuclides and their gaseous daughter decay products in the uranium and thorium series [5].

Each sample containing soil grain weighing about 200 $\mathrm{g}$ was stored in standardized polyethylene containers. The containers were sealed to avoid any possibility of out gassing of radon and kept over a period than one month to make sure the samples attained the radioactive equilibrium between ${ }^{226} \mathrm{Ra}$ with its decay products in the uranium series. It was assumed that ${ }^{232} \mathrm{Th}$ is in secular equilibrium with ${ }^{228} \mathrm{Ra}$. For the measurement of activity concentrations of naturally occurring radionuclides of ${ }^{226} \mathrm{Ra},{ }^{232} \mathrm{Th}$, and ${ }^{40} \mathrm{~K}$ in soil samples, (HPGe) detector based gamma ray spectrometer with a relative efficiency of $30 \%$ was employed. (HPGe) Detector was coupled with a Canberra multichannel analyzer (MCA). The resolution Full width of half maximum (FWHM) of the spectrometry system was $1.8 \mathrm{keV}$ at $1332 \mathrm{keV}$ gammaray line of ${ }^{60} \mathrm{Co}$. Spectrum of every sample was collected for 54,000 seconds $(15 \mathrm{~h})$. A typical spectrum is shown Figure 1 for sample G14. Spectrum analysis was performed with computer software and activity concentrations of three natural radionuclides were determined. To reduce the background effect, the detector was shielded in a $10 \mathrm{~cm}$ wall lead covering lined with $2 \mathrm{~mm}$ copper and tow mm cadmium foils. In order to determine the background radiation distribution in the environment around the detector, an empty sealed container was counted for 10 hours [6].

\section{RESULTS AND DISCUSSION}

\subsection{Norm in Building Materials}

The determination of the presence of radionuclides and calculation of their activities were based on the following gamma-ray transitions (in $\mathrm{keV}$ ): the ${ }^{226} \mathrm{Ra}$ activities (or ${ }^{238} \mathrm{U}$ activities for samples assumed to be in radioactive equilibrium) were estimated from ${ }^{234} \mathrm{Th}(92.38$ $\mathrm{keV}, 5.6 \%)$, while $\gamma$-energies of ${ }^{214} \mathrm{~Pb}(351.9 \mathrm{keV}, 35.8 \%)$ and ${ }^{214} \mathrm{Bi}(609.3,45 \%),(1764.5 \mathrm{keV}, 17 \%)$ and ${ }^{226} \mathrm{Ra}$ (185.99 KeV, 3.5\%) were used to estimate the concentration of ${ }^{226} \mathrm{Ra}$. The gamma ray energies of ${ }^{212} \mathrm{~Pb}(238.6$ 


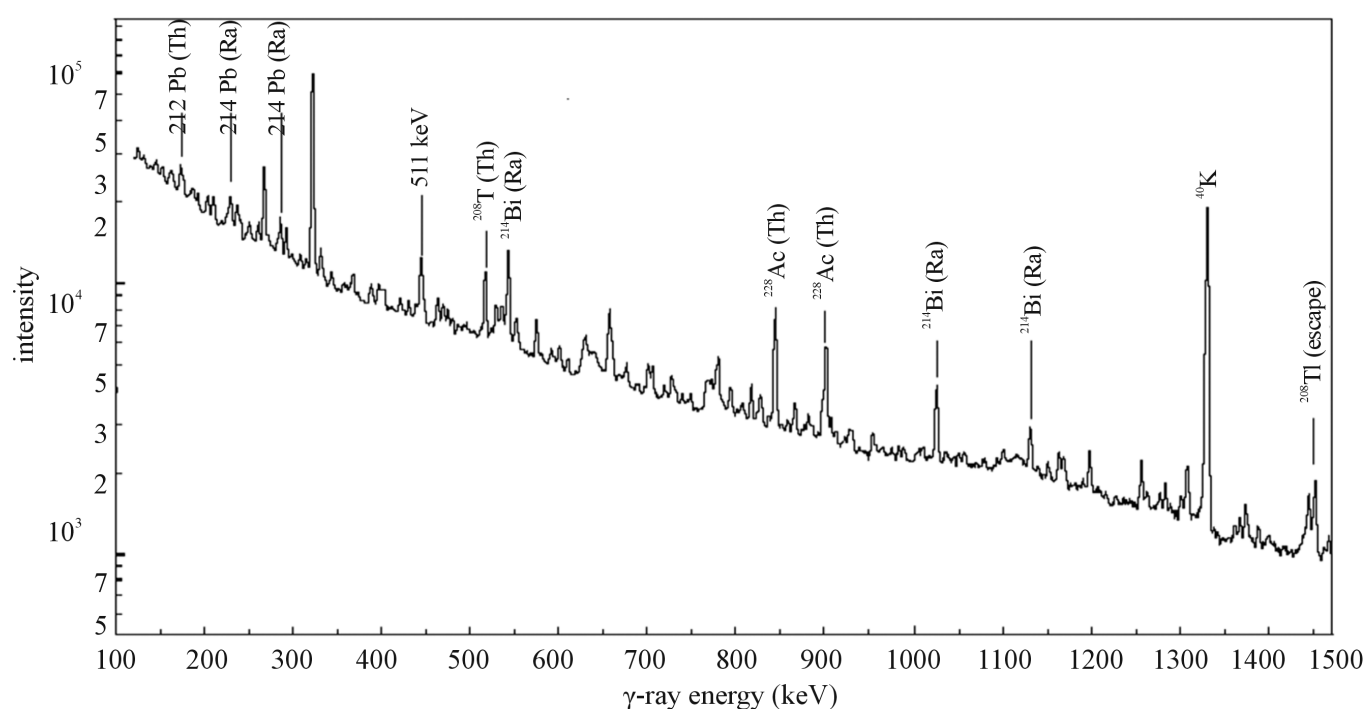

Figure 1. $\gamma$-Ray spectrum for gypsum sample G14.

$\mathrm{keV}, 45 \%$ ), and ${ }^{228} \mathrm{Ac}$ (338.4 keV, 12.3\%), (911.07 keV, $29 \%)$, (968.90 keV, 17\%) were used to estimate the concentration of ${ }^{232} \mathrm{Th}$. The natural abundance of ${ }^{235} \mathrm{U}$ is only $0.72 \%$ of the total uranium content and hence was not considered in the present study. The activity concentrations of ${ }^{40} \mathrm{~K}$ were measured directly by its own gamma rays $(1460.8 \mathrm{keV}, 10.7 \%)$. The detector energy resolution is not sufficient to easily separate these peaks. Therefore, the concentrations of ${ }^{235} \mathrm{U}$ were calculated by subtracting the fraction of ${ }^{226}$ Ra using Equation (1) [7]:

$$
A_{U-235}=\left[1.75\left(C R_{T .186}\right) / \varepsilon_{186}\right]-0.063 A_{\mathrm{Ra}-226}
$$

where: $C R_{T}$ : is the total count rate (counts $\cdot \mathrm{sec}^{-1}$ ) in the $186 \mathrm{KeV}$ energy peak;

$\varepsilon$ : detection efficiency; and

$A_{\text {Ra-226: }}$ activity concentration of ${ }^{226} \mathrm{Ra}$.

Determination of activity concentrations was calculated using the Equation (2) [8].

$$
A=C / M \beta \varepsilon
$$

where: $C$ : is the net peak area of specific gamma ray energy (count per second).

$M$ : is the mass of the samples $(\mathrm{kg})$.

$B$ : is the transition probability of gamma-decay. And,

$\varepsilon$ : is the detector efficiency at the specific gamma-ray energy.

During the last three decades, there has been an increasing interest to the study of the radioactivity of different building materials. Several national surveys were conducted to establish the radioactivity concentrations in raw material, industrial by-products and building materials and their radon exhalation rate [3]. The production process and the origin of the raw materials are the most important factors that determine the radionuclide activity concentrations in the construction materials. Different types of building materials were found to contain radionuclide concentration of over two to three orders of magnitude.

\section{2. ${ }^{226} \mathrm{Ra},{ }^{232} \mathrm{Th}$ and ${ }^{40} \mathrm{~K}$ Concentration in Building Materials}

The activity concentrations of NORM in building materials vary according to the type and origin of the building material (Tables 1 and 2). It shows the typical and maximum activity concentrations in common building materials and industrial by-products used for building materials in Europe, e.g. typical and maximum activity concentrations in natural gypsum are 10, 10, 80 (Bq/kg) and 70, 100, $200(\mathrm{~Bq} / \mathrm{kg})$ for ${ }^{226} \mathrm{Ra},{ }^{232} \mathrm{Th}$ and ${ }^{40} \mathrm{~K}$, respectively [3]. The average activity concentrations of the natural radionuclides of gypsum both as structural materials or covering layers from different countries all over the world are shown in Table 3 for comparison. This comparison was indicated that the variations in activity concentrations of radium isotopes content in NORM samples of different origins could be due to geological considerations (Table 4). Comparison of radionuclide concentrations $\left(\mathrm{Bq} \cdot \mathrm{kg}^{-1}\right)$ in gypsum samples in the present work with those obtained by previous studies in Egypt.

It is clearly the mean activity concentrations of ${ }^{226} \mathrm{Ra}$, ${ }^{232} \mathrm{Th}$ and ${ }^{40} \mathrm{~K}$ of samples in a present study are slightly lower $(499.29 \pm 11.53,42.27 \pm 2.22$ and $91.97 \pm 2.61$ $\mathrm{Bq} \cdot \mathrm{kg}^{-1}$ respectively) than those reported by [15] for gypsum from Qena City, Upper Egypt. While our results proved that the mean activity concentrations of ${ }^{226} \mathrm{Ra}$, ${ }^{232} \mathrm{Th}$ and ${ }^{40} \mathrm{~K}$ much higher than those reported by [4] in Egypt.

The total error includes the statistical uncertainty in the peak area, calibration and counting error. Table 5 
Table 1. Typical and maximum activity concentrations in common building materials and industrial by-products used for building materials in Europe [RP-112 1999].

\begin{tabular}{ccccccc}
\hline \multirow{2}{*}{ Material } & \multicolumn{2}{c}{${ }^{40} \mathbf{K}$} & \multicolumn{2}{c}{${ }^{232} \mathbf{T h}$} & \multicolumn{2}{c}{${ }^{226} \mathbf{R a}$} \\
\cline { 2 - 7 } & Max. & Typical & Max. & Typical & Max. Typical \\
\hline Concrete & 1600 & 400 & 190 & 30 & 240 & 40 \\
$\begin{array}{c}\text { Aerated and } \\
\text { light-weight concrete }\end{array}$ & 1600 & 430 & 190 & 40 & 2600 & 60 \\
Clay (red) bricks & 2000 & 670 & 200 & 50 & 200 & 50 \\
Sand-lime bricks & 700 & 330 & 30 & 10 & 25 & 10 \\
Natural building stones & 4000 & 640 & 310 & 60 & 500 & 60 \\
Natural gypsum & 200 & 80 & 100 & 10 & 70 & 10 \\
\hline
\end{tabular}

Table 2. Most common industrial by-products used in building materials in Europe [RP-112 1999].

\begin{tabular}{ccccccc}
\hline \multirow{2}{*}{ Material } & \multicolumn{2}{c}{${ }^{40} \mathbf{K}$} & \multicolumn{2}{c}{${ }^{232} \mathbf{T h}$} & \multicolumn{2}{c}{${ }^{226} \mathbf{R a}$} \\
\cline { 2 - 7 } & Max. & Typical & Max. & Typical & Max. & Typical \\
\hline Phospho gypsum & 300 & 60 & 160 & 20 & 1100 & 390 \\
Blast furnace slag & 1000 & 240 & 340 & 70 & 2100 & 270 \\
Coal fly ash & 1500 & 650 & 300 & 100 & 1100 & 180 \\
\hline
\end{tabular}

Table 3. Comparison of radionuclide concentrations $\left(\mathrm{Bq} \cdot \mathrm{kg}^{-1}\right)$ in gypsum samples with those obtained in other published data.

\begin{tabular}{ccccc}
\hline Country & ${ }^{40} \mathbf{K}$ & ${ }^{232} \mathbf{T h}$ & ${ }^{226} \mathbf{R a}$ & References \\
\hline China & 35 & 35 & 370 & {$[\mathbf{9 , 1 0 ]}$} \\
Nordic Countries & 40 & 49 & 80 & {$[\mathbf{9 ]}$} \\
West Germany & 14 & 18.5 & 259 & {$[\mathbf{1 1 ]}$} \\
Finland & 37 & 43 & 1034 & {$[\mathbf{1 1 ]}$} \\
Bangladesh & 88.1 & 68.2 & 256.4 & {$[\mathbf{1 2 ]}$} \\
Spain & 14.1 & 17.39 & 266.77 & {$[\mathbf{1 3 ]}$} \\
Turkey & 44.5 & 3.6 & 10.8 & {$[\mathbf{1 4}]$} \\
USSR & 14.8 & 140.8 & 259 & {$[\mathbf{1 1}]$} \\
India & 22 & 9.3 & 233 & {$[\mathbf{1 1}]$} \\
\hline
\end{tabular}

summaries the results for the range and mean natural activity concentrations of ${ }^{238} \mathrm{U}$; ${ }^{226} \mathrm{Ra} ;{ }^{232} \mathrm{Th}$ and ${ }^{40} \mathrm{~K}$ for different gypsum samples in $\mathrm{Bq} / \mathrm{kg}$. The lowest mean value of the ${ }^{238} \mathrm{U}$ concentration is $7.5 \pm 0.54(\mathrm{~Bq} / \mathrm{kg})$ in a sample $\mathrm{G} 1$, while the highest is $74.80 \pm 3.15(\mathrm{~Bq} / \mathrm{kg})$ in sample G14. The lowest mean value of the ${ }^{226} \mathrm{Ra}$ concentration is $10.73 \pm 0.63(\mathrm{~Bq} / \mathrm{kg})$ in sample $\mathrm{G} 1$, while the highest is $170.42 \pm 5.04(\mathrm{~Bq} / \mathrm{kg})$ in sample G5. It can also be seen that the highest mean value of ${ }^{232} \mathrm{Th}$ is 70.80 $\pm 2.75(\mathrm{~Bq} / \mathrm{kg})$ in sample G5 and the lowest mean value is
Table 4. Comparison of activity concentration (Bq/kg) of gypsum used in Egypt with those of previous studies.

\begin{tabular}{ccccc}
\hline Countries & ${ }^{226} \mathbf{R a}$ & ${ }^{232} \mathbf{T h}$ & ${ }^{40} \mathbf{K}$ & References \\
\hline Egypt (1) & 91.97 & 42.27 & 499.29 & Present work \\
Egypt (3) & 105 & 45 & 500 & [15] \\
Egypt (4) & 31.7 & 55 & 116 & [4] \\
\hline
\end{tabular}

Table 5. Activity concentration range $(\mathrm{Bq} / \mathrm{kg})$ of gypsum in Egypt current works.

\begin{tabular}{crrrr}
\hline Sample & $\mathbf{A}_{\mathbf{k}}(\mathbf{B q} / \mathbf{K g})$ & $\mathbf{A}_{\mathbf{T h}}(\mathbf{B q} / \mathbf{K g})$ & $\mathbf{A}_{\mathbf{R a}}(\mathbf{B q} / \mathbf{K g})$ & $\mathbf{A}_{\mathbf{U}}(\mathbf{B q} / \mathbf{K g})$ \\
\hline G1 & $307.5 \pm 8.32$ & $3.1 \pm 0.05$ & $10.73 \pm 0.63$ & $7.51 \pm 0.54$ \\
G2 & $365.6 \pm 9.91$ & $11.7 \pm 0.64$ & $14.5 \pm 0.76$ & $9.7 \pm 0.57$ \\
G3 & $681.3 \pm 19.07$ & $59.8 \pm 1.81$ & $119.3 \pm 3.31$ & $43.2 \pm 1.85$ \\
G4 & $433.2 \pm 12.09$ & $41.4 \pm 1.69$ & $87.6 \pm 2.56$ & $23.5 \pm 1.45$ \\
G5 & $689.1 \pm 19.07$ & $70.8 \pm 2.75$ & $170.42 \pm 5.04$ & $48.3 \pm 1.91$ \\
G6 & $417.7 \pm 11.68$ & $39.3 \pm 1.76$ & $75.3 \pm 2.45$ & $34.6 \pm 1.57$ \\
G7 & $528.4 \pm 14.91$ & $61.2 \pm 2.31$ & $136.2 \pm 4.12$ & $74.8 \pm 2.45$ \\
G8 & $564.3 \pm 15.75$ & $49.1 \pm 2.17$ & $121.9 \pm 3.24$ & $37.9 \pm 1.67$ \\
G9 & $531.3 \pm 14.92$ & $56.7 \pm 2.28$ & $138.1 \pm 4.12$ & $22.1 \pm 1.43$ \\
G10 & $678.1 \pm 18.65$ & $67.4 \pm 2.32$ & $97.7 \pm 2.81$ & $61.9 \pm 2.33$ \\
G11 & $349.2 \pm 9.71$ & $23.8 \pm 1.46$ & $23.6 \pm 1.46$ & $19.4 \pm 1.89$ \\
G12 & $689.1 \pm 19.05$ & $52.9 \pm 2.16$ & $74.0 \pm 2.38$ & $49.7 \pm 2.11$ \\
G13 & $431.9 \pm 12.08$ & $58.1 \pm 1.72$ & $121.1 \pm 3.23$ & $61.9 \pm 2.33$ \\
G14 & $654.6 \pm 18.37$ & $63.8 \pm 2.41$ & $148.3 \pm 4.16$ & $74.8 \pm 3.15$ \\
G15 & $301.3 \pm 8.32$ & $16.5 \pm 0.86$ & $132.5 \pm 4.06$ & $10.4 \pm 0.62$ \\
G16 & $407.7 \pm 11.27$ & $31.3 \pm 1.06$ & $116.7 \pm 3.27$ & $27.2 \pm 1.57$ \\
G17 & $517.4 \pm 14.50$ & $18.2 \pm 1.20$ & $39.8 \pm 1.69$ & $25.9 \pm 1.51$ \\
G18 & $439.3 \pm 10.12$ & $35.8 \pm 1.56$ & $27.8 \pm 0.48$ & $44.62 \pm 1.74$ \\
Min & $\mathbf{3 0 1 . 3} \pm \mathbf{8 . 3 2}$ & $\mathbf{3 . 1} \pm \mathbf{0 . 0 5}$ & $\mathbf{1 0 . 7 3} \pm \mathbf{0 . 6 3}$ & $\mathbf{7 . 5 1} \pm \mathbf{0 . 5 4}$ \\
Max & $\mathbf{6 8 9 . 1} \pm \mathbf{1 9 . 0 7}$ & $\mathbf{7 0 . 8} \pm \mathbf{2 . 7 5}$ & $\mathbf{1 7 0 . 4 2} \pm \mathbf{5 . 0 4}$ & $\mathbf{7 4 . 8 0} \pm \mathbf{3 . 1 5}$ \\
Mean & $\mathbf{4 9 9 . 2 9} \pm \mathbf{1 1 . 5 3} \mathbf{4 2 . 2 7} \pm \mathbf{2 . 2 2}$ & $\mathbf{9 1 . 9 7} \pm \mathbf{2 . 6 1}$ & $\mathbf{3 7 . 6 2} \pm \mathbf{1 . 6 7}$ \\
Standard & $\mathbf{1 3 1 . 5 8}$ & $\mathbf{2 0 . 3}$ & $\mathbf{4 8 . 8 3}$ & $\mathbf{2 0 . 7}$ \\
Deviation & & & &
\end{tabular}

$3.10 \pm 0.05(\mathrm{~Bq} / \mathrm{kg})$ in a sample G1. The highest and lowest mean values of ${ }^{40} \mathrm{~K}$ are $689.10 \pm 19.07$ and 301.30 $\pm 8.32(\mathrm{~Bq} / \mathrm{kg})$ in samples G5 and G15, respectively.

Uncertainties are given within one standard deviation.

\subsection{Radon Exhalation from in Building Materials}

The radon emanation power or emanation coefficient, 
denoted by $\zeta$, is defined as the fraction of ${ }^{222} \mathrm{Rn}$ produced by the disintegration of ${ }^{226} \mathrm{Ra}$ in the grains of the material that can escape from it. The emanation power is dimensionless and ranges from 0 (no radon escapes from the material) to 1 (all radon escapes). The rate of radon exhalation is proportional to the gradient of the radon concentration in the internal pores.

$$
\mathrm{E}=-\mathrm{D} \cdot \mathrm{dC} /\left.\mathrm{dx}\right|_{\mathrm{x}=1}
$$

where $\mathrm{D}$ is the effective diffusion coefficient and $\mathrm{dC} / \mathrm{dx}$ is the change from the radon concentration. The principal factors affecting the radon exhalation rate (from a building material) per unit activity concentration of ${ }^{226} \mathrm{Ra}$ are the porosity and the density as the material, the diffusion coefficient, the water content, the age and the composition as the material (as seen in Equation (4)).

For the following boundary conditions:

$\mathrm{C}(1)=\mathrm{C}(-1) 0$ and $(\mathrm{dx} / \mathrm{dC})=0$ the radon exhalation rated $E$ :

$$
E=\zeta \cdot C_{\mathrm{Ra}} \cdot \rho \cdot \sqrt{\lambda} D / P \cdot \tan h(\sqrt{\lambda} D / P \cdot I)
$$

where $\rho$ is the density, $l$ is the half thickness as the material, $P$ is the porosity of the material, $\lambda$ is the decay constant of ${ }^{222} \mathrm{Rn}$ and $\zeta \cdot C_{\mathrm{Ra}}$ is the effective radium concentration (the fraction of the total radium which contributes to radon exhalation).

Radon exhalation from building materials has been studied since the early 70's as one of the contributors to the indoor radon concentration. In Hong Kong and The Netherlands was found to be the major contributor to the population radon dose $[16,17]$. The radon exhalation rate from concrete varies according to the age of the concrete, the water content and the addition of fly ash. The exhalation increases almost linearly with the moisture content up to $50 \%$ - $60 \%$, peaks at $70 \%-80 \%$ and decreases steeply for higher moisture levels. The addition of fly ash to concrete generally increases the ${ }^{226} \mathrm{Ra}$ activity, while the radon exhalation rate slightly increases or even decreases [18-20].

Several methods for exhalation measurements have been developed, as contrary the well established gamma spectrometry procedures for the measurements of ${ }^{226} \mathrm{Ra}$, ${ }^{232} \mathrm{Th}$ and ${ }^{40} \mathrm{~K}$. Measurements of radon from the exhaling area into a closed chamber, purge and trap of the radon, radon flux measurements from the material surface and in-situ measurements have been reported.

\subsection{Assessment of Radiation Hazard from Egyptian Gypsum}

1) Estimation of the Absorbed Dose Rate (D), Annual Indoor Effective Gamma Dose Rate (DE) and Radium Equivalent Activity ( $\left(\mathbf{a}_{\mathrm{eq}}\right)$ :

The absorbed dose rate (D) in air upon a height of 1.0 $\mathrm{m}$ above the ground from the radionuclides ${ }^{40} \mathrm{~K}$ and also ${ }^{232} \mathrm{Th}$ and the ${ }^{238} \mathrm{U}$ decay series, were calculated using Equation (6), if the naturally occurring radionuclides are uniformly distributed [21,22].

$$
\mathrm{D}=0.52813 \mathrm{C}_{\mathrm{Th}}+0.38919 \mathrm{C}_{\mathrm{Ra}}+0.03861 \mathrm{C}_{\mathrm{K}}
$$

where: $\mathrm{C}_{\mathrm{Ra}}, \mathrm{C}_{\mathrm{Th}}$, and $\mathrm{C}_{\mathrm{K}}$ are the activity concentration of ${ }^{226} \mathrm{Ra},{ }^{232} \mathrm{Th}$, and ${ }^{40} \mathrm{~K}$ in $(\mathrm{Bq} / \mathrm{kg})$, respectively. Results of $\gamma$-radiation absorbed dose rate are shown in Table 6. Average values of calculated absorbed dose rates in samples under investigation are ranged between $19.69 \pm 0.40$ to $151.43 \pm 4.13 \mathrm{nGyh}^{-1}$; it was found that an average value of $151.43 \pm 4.13 \mathrm{nGy} / \mathrm{h}$, which is higher by a factor of 2.75 than world average of $55 \mathrm{nGyh}^{-1}$ [23].

Annual effective dose rates values of the absorbed dose rate were used in the calculation of annual outdoor effective dose rate considering some correction factors. A conversion factor ( $\mathrm{CF}=0.7 \mathrm{~Sv} / \mathrm{Gy}$ ) was applied for conversion of the absorbed dose in air to the corresponding effective dose. The outdoor occupancy factor

\begin{tabular}{|c|c|c|c|}
\hline Sample & $\mathrm{Ra}_{\mathrm{eq}}(\mathrm{Bq} / \mathbf{K g})$ & $\mathrm{D}\left(\mathrm{nGyh}^{-1}\right)$ & $\mathrm{DE}$ indoor $(\mathrm{mSv} / \mathrm{y})$ \\
\hline G1 & $38.81 \pm 1.68$ & $19.69 \pm 0.40$ & $0.10 \pm 0.003$ \\
\hline G2 & $59.38 \pm 2.30$ & $29.21 \pm 0.53$ & $0.14 \pm 0.003$ \\
\hline G3 & $257.27 \pm 7.25$ & $120.66 \pm 3.30$ & $0.59 \pm 0.07$ \\
\hline G4 & $180.16 \pm 5.35$ & $84.25 \pm 2.52$ & $0.41 \pm 0.04$ \\
\hline G5 & $324.7 \pm 9.42$ & $151.43 \pm 4.13$ & $0.74 \pm 0.08$ \\
\hline G6 & $163.66 \pm 4.59$ & $76.61 \pm 2.47$ & $0.38 \pm 0.04$ \\
\hline G7 & $264.4 \pm 7.32$ & $122.96 \pm 3.24$ & $0.60 \pm 0.08$ \\
\hline G8 & $235.56 \pm 6.60$ & $110.34 \pm 3.18$ & $0.54 \pm 0.07$ \\
\hline G9 & $260.09 \pm 7.26$ & $121.17 \pm 3.23$ & $0.59 \pm 0.08$ \\
\hline G10 & $246.3 \pm 6.97$ & $115.27 \pm 3.21$ & $0.57 \pm 0.07$ \\
\hline G11 & $84.52 \pm 2.52$ & $40.24 \pm 1.72$ & $0.20 \pm 0.02$ \\
\hline G12 & $202.71 \pm 6.32$ & $95.77 \pm 2.75$ & $0.47 \pm 0.05$ \\
\hline G13 & $237.44 \pm 6.61$ & $110.04 \pm 3.18$ & $0.54 \pm 0.06$ \\
\hline G14 & $289.94 \pm 8.06$ & $135.43 \pm 4.33$ & $0.66 \pm 0.08$ \\
\hline G15 & $179.3 \pm 4.95$ & $84.03 \pm 2.52$ & $0.41 \pm 0.04$ \\
\hline G16 & $192.85 \pm 5.35$ & $90.35 \pm 2.77$ & $0.44 \pm 0.04$ \\
\hline G17 & $105.67 \pm 3.05$ & $51.27 \pm 1.96$ & $0.25 \pm 0.02$ \\
\hline G18 & $112.82 \pm 3.17$ & $53.39 \pm 2.17$ & $0.26 \pm 0.02$ \\
\hline Min & $38.81 \pm 1.68$ & $19.69 \pm 0.40$ & $0.10 \pm 0.003$ \\
\hline Max & $324.7 \pm 9.42$ & $151.43 \pm 4.13$ & $0.74 \pm 0.08$ \\
\hline Mean & $190.87 \pm 5.34$ & $89.56 \pm 2.61$ & $0.44 \pm 0.04$ \\
\hline
\end{tabular}

Table 6. Absorbed dose rate $(\mathrm{Bq} / \mathrm{kg})$ and Radium equivalent activity of gypsum in Egypt. 
$(\mathrm{OF}=0.8)$ was taken into account, since the people spend most of their time (80\%) in buildings. Finally, the ratio of indoor to outdoor gamma dose rates $(\mathrm{R}=1.4)$ was also applied as used by other investigators [24] to calculate the annual indoor effective gamma dose rate $(\mathrm{DE})$ in $(\mathrm{Sv} / \mathrm{y})$ as given to follow:

$$
\mathrm{DE}=\mathrm{D} \times \mathrm{CF} \times \mathrm{OF} \times \mathrm{R} \times \mathrm{t}
$$

where: $D$ is the dose rate in $\left(G y / h^{-1}\right)$ and $\mathbf{t}$ is the duration of the exposure $(=365 \times 24 \mathrm{~h})$. Results for indoor annual effective dose rates are shown in Table 6. It ranged from $0.10 \pm 0.003$ to $0.74 \pm 0.08 \mathrm{mSv} / \mathrm{y}$ with an average value of $0.44 \pm 0.04 \mathrm{mSv} / \mathrm{y}$. Finally all samples gave annual effective dose lower than the world wide indoor average annual effective dose $1 \mathrm{mSv} / \mathrm{y}$.

It is important to assess the gamma radiation hazards to persons associated with the used sand, limestone, shale and gypsum for building materials. To represent the activities due to ${ }^{226} \mathrm{Ra},{ }^{232} \mathrm{Th}$ and ${ }^{40} \mathrm{~K}$ by a single quantity which takes into account the radiation hazards which may be caused a common index called the radium equivalent activity $\left(\mathrm{Ra}_{\mathrm{eq}}\right)$ in $\mathrm{Bq} \cdot \mathrm{kg}^{-1}$ has been introduced [25-27], defined as:

$$
\mathrm{R}_{\mathrm{eq}}=\mathrm{C}_{\mathrm{Ra}}+1.43 \mathrm{C}_{\mathrm{Th}}+0.077 \mathrm{C}_{\mathrm{K}}
$$

where: $\mathrm{C}_{\mathrm{Ra}}, \mathrm{C}_{\mathrm{Th}}$, and $\mathrm{C}_{\mathrm{K}}$ are the activity concentration of ${ }^{226} \mathrm{Ra},{ }^{232} \mathrm{Th}$, and ${ }^{40} \mathrm{~K}$ in $(\mathrm{Bq} / \mathrm{kg})$, respectively. This index $\left(\mathrm{R}_{\mathrm{eq}}\right)$ is related to both internal dose due to radon and external gamma dose [20], and should have the highest value of $370 \mathrm{~Bq} / \mathrm{kg}$ for safe use of the building materials. As reference, the permissible dose limit for public which is recommended by ICRP (1991) [28] are $1.5 \mathrm{mSv} \cdot \mathrm{y}^{-1}$ or equivalent to $370 \mathrm{~Bq} \cdot \mathrm{kg}^{-1}$. The mean calculated $\mathrm{Ra}_{\mathrm{eq}}$ values are shown in Table 6 for the different gypsum types and the regions from where they were collected. The minimum (38.81 $\left.\pm 168 \mathrm{~Bq} \cdot \mathrm{kg}^{-1}\right)$ and the maximum $\left(324.70 \pm 9.42 \mathrm{~Bq} \cdot \mathrm{kg}^{-1}\right.$ ) values of $\mathrm{Ra}_{\mathrm{eq}}$ were found in $\mathrm{G}(1)$ and $\mathrm{G}(5)$ gypsum types, respectively. The mean $\mathrm{Ra}_{\mathrm{eq}}$ values of all the measured samples were almost lower than limit value of $370 \mathrm{~Bq} \cdot \mathrm{kg}^{-1}$ recommended by the Organization for Economic Cooperation and Development.

\section{2) Hazard Indices}

To limit the external $\gamma$-radiation dose from building materials to $1.5 \mathrm{mSv} / \mathrm{yr}$, the external hazard index $\left(\mathrm{H}_{\mathrm{ex}}\right)$ is defined by some workers, Beretka and Mathew introduced a hazard index for the external and internal gamma radiation dose from building materials as given bellow [29].

The external hazard index is obtained from $\mathrm{Ra}_{\mathrm{eq}}$ expression through the supposition that its maximum value allowed (equal to unity) corresponds to the upper limit of $\mathrm{Ra}_{\mathrm{eq}}\left(370 \mathrm{~Bq} \cdot \mathrm{kg}^{-1}\right)$. Then, the external hazard index can be defined as:

$$
\mathrm{H}_{\mathrm{ex}}=\left(\mathrm{C}_{\mathrm{U}} / 370+\mathrm{C}_{\mathrm{Th}} / 259+\mathrm{C}_{\mathrm{K}} / 4810\right)<1
$$

In addition to the external hazard, radon and its shortlived products are also hazardous to the respiratory organs. The internal exposure to radon and its daughter products is quantified by the internal hazard index $\left(\mathrm{H}_{\text {in }}\right)$ which is given by the equation:

$$
\mathrm{H}_{\mathrm{in}}=\left(\mathrm{C}_{\mathrm{U}} / 185+\mathrm{C}_{\mathrm{Th}} / 259+\mathrm{C}_{\mathrm{K}} / 4810\right)<1
$$

where $C_{U}, C_{T h}$ and $C_{K}$ are the specific activities of ${ }^{238} U$, ${ }^{232} \mathrm{Th}$ and ${ }^{40} \mathrm{~K}$ in $\mathrm{Bq} \cdot \mathrm{kg}^{-1}$, respectively. The calculated values of external hazard index obtained in this study ranged from $0.1 \pm 0.002$ to $0.58 \pm 0.06$ with mean value of 0.37 , Table 7 . If the maximum concentration of radium is half that of the normal acceptable limit, then $\mathrm{H}_{\text {in }}$ will be less than 1.0. For the safe use as a material in for the construction of dwellings, $\mathrm{H}_{\text {in }}$ should be less than unity. The calculated values of $H_{\text {in }}$ for the studied gypsum samples range from $0.12 \pm 0.005$ (G1) to $0.79 \pm$ 0.09 (G14). Once again, all these values are less than unity.

\section{3) Representative Gamma Index $\left(\mathbf{I}_{\gamma}\right)$ and $\left(\mathrm{I}_{\alpha}\right)$}

Number of indices dealing with the assessment of the excess gamma radiation arising from building materials such as external and internal hazard indices and gamma concentration indices have been proposed by several investigators [30-33]. In this study, the gamma index $\left(\mathrm{I}_{y}\right)$ It was calculated as proposed by the European Commission [30]:

$$
\mathrm{I}_{\gamma}=\mathrm{C}_{\mathrm{Ra}} / 150+\mathrm{C}_{\mathrm{Th}} / 100+\mathrm{C}_{\mathrm{K}} / 1500\left(\mathrm{~Bq} \cdot \mathrm{kg}^{-1}\right)
$$

where $\mathrm{C}_{\mathrm{Ra}}, \mathrm{C}_{\mathrm{Th}}$ and $\mathrm{C}_{\mathrm{K}}$ are the activity concentrations of ${ }^{226} \mathrm{Ra}$, ${ }^{232} \mathrm{Th}$ and ${ }^{40} \mathrm{~K}$ in $\mathrm{Bq} \cdot \mathrm{kg}^{-1}$, respectively. $\mathrm{I} \leq 1$ corresponds to a does creation of $1 \mathrm{mSv} \cdot \mathrm{y}^{-1}$, while $\mathrm{I} \leq 0.5$ corresponds to $0.3 \mathrm{mSv} \cdot \mathrm{y}^{-1}$. The mean values of $\mathrm{I}_{\nu}$ calculated from the measured activity concentration of ${ }^{226} \mathrm{Ra}$, ${ }^{232} \mathrm{Th}$ and ${ }^{40} \mathrm{~K}$ are presented in Table 7 for different gypsum samples. The mean calculated values of $\mathrm{I}_{\gamma}$ for the studied samples varied in the range between $0.31 \pm 0.03$ $-2.3 \pm 0.19\left(\mathrm{~Bq} \cdot \mathrm{kg}^{-1}\right)$ which were higher than the critical value of unity.

So far, several alpha indices have been proposed to assess the exposure level due to radon inhalation originating from building materials [30]. The alpha index was determined by the following formula:

$$
\mathrm{I}_{\alpha}=\mathrm{C}_{\mathrm{Ra}} / 200\left(\mathrm{~Bq} \cdot \mathrm{kg}^{-1}\right)
$$

where $\mathrm{C}_{\mathrm{Ra}}\left(\mathrm{Bq} \cdot \mathrm{kg}^{-1}\right)$ is the activity concentration of ${ }^{226} \mathrm{Ra}$ assumed in equilibrium with ${ }^{238} \mathrm{U}$. The recommended exemption and upper level of ${ }^{226} \mathrm{Ra}$ activity concentrations in building materials are 100 and $200 \mathrm{~Bq} \cdot \mathrm{kg}^{-1}$, respectively, as suggested by ICRP [30]. These considerations are reflected in the alpha index. The recommended upper limit concentration of ${ }^{226} \mathrm{Ra}$ is $200 \mathrm{~Bq} \cdot \mathrm{kg}^{-1}$, for 
Table 7. The external and internal hazard and $\mathrm{I}_{\text {gamma }}, \mathrm{I}_{\text {alpha }}$ of gypsum in Egypt.

\begin{tabular}{|c|c|c|c|c|c|c|}
\hline Sample & $\mathbf{H}_{\mathrm{ex}}$ & $\mathbf{H}_{\text {in }}$ & $\mathbf{I}_{\gamma}$ & $\mathbf{I}_{\alpha}$ & eTh/eU (ppm) & eU/eRa (ppm) \\
\hline G1 & $0.10 \pm 0.002$ & $0.12 \pm 0.005$ & $0.31 \pm 0.03$ & $0.05 \pm 0.002$ & $1.02 \pm 0.07$ & $0.70 \pm 0.08$ \\
\hline G2 & $0.15 \pm 0.004$ & $0.17 \pm 0.007$ & $0.46 \pm 0.04$ & $0.07 \pm 0.003$ & $1.20 \pm 0.09$ & $0.67 \pm 0.07$ \\
\hline G3 & $0.49 \pm 0.05$ & $0.61 \pm 0.07$ & $1.85 \pm 0.17$ & $0.60 \pm 0.07$ & $0.13 \pm 0.006$ & $0.36 \pm 0.03$ \\
\hline G4 & $0.31 \pm 0.03$ & $0.38 \pm 0.03$ & $1.29 \pm 0.11$ & $0.44 \pm 0.04$ & $0.38 \pm 0.03$ & $0.27 \pm 0.02$ \\
\hline G5 & $0.55 \pm 0.06$ & $0.68 \pm 0.08$ & $2.3 \pm 0.22$ & $0.85 \pm 0.10$ & $0.16 \pm 0.007$ & $0.28 \pm 0.02$ \\
\hline G6 & $0.33 \pm 0.03$ & $0.43 \pm 0.04$ & $1.17 \pm 0.10$ & $0.38 \pm 0.04$ & $0.62 \pm 0.07$ & $0.46 \pm 0.05$ \\
\hline G7 & $0.55 \pm 0.06$ & $0.75 \pm 0.08$ & $1.87 \pm 0.17$ & $0.68 \pm 0.09$ & $0.20 \pm 0.02$ & $0.55 \pm 0.06$ \\
\hline G8 & $0.41 \pm 0.04$ & $0.51 \pm 0.06$ & $1.68 \pm 0.16$ & $0.61 \pm 0.08$ & $0.15 \pm 0.007$ & $0.31 \pm 0.03$ \\
\hline G9 & $0.39 \pm 0.04$ & $0.45 \pm 0.04$ & $1.84 \pm 0.17$ & $0.69 \pm 0.09$ & $0.36 \pm 0.03$ & $0.16 \pm 0.004$ \\
\hline G10 & $0.57 \pm 0.06$ & $0.74 \pm 0.08$ & $1.78 \pm 0.16$ & $0.49 \pm 0.05$ & $0.09 \pm 0.001$ & $0.63 \pm 0.07$ \\
\hline G11 & $0.22 \pm 0.02$ & $0.27 \pm 0.02$ & $0.63 \pm 0.07$ & $0.12 \pm 0.005$ & $0.68 \pm 0.07$ & $0.82 \pm 0.15$ \\
\hline G12 & $0.48 \pm 0.05$ & $0.62 \pm 0.07$ & $1.48 \pm 0.15$ & $0.37 \pm 0.04$ & $0.38 \pm 0.04$ & $0.67 \pm 0.08$ \\
\hline G13 & $0.48 \pm 0.05$ & $0.65 \pm 0.08$ & $1.68 \pm 0.11$ & $0.61 \pm 0.03$ & $0.42 \pm 0.05$ & $0.51 \pm 0.06$ \\
\hline G14 & $0.58 \pm 0.06$ & $0.79 \pm 0.09$ & $2.06 \pm 0.19$ & $0.74 \pm 0.09$ & $0.05 \pm 0.001$ & $0.50 \pm 0.06$ \\
\hline G15 & $0.15 \pm 0.004$ & $0.18 \pm 0.001$ & $1.25 \pm 0.14$ & $0.66 \pm 0.08$ & $0.54 \pm 0.07$ & $0.08 \pm 0.001$ \\
\hline G16 & $0.28 \pm 0.02$ & $0.35 \pm 0.03$ & $1.36 \pm 0.20$ & $0.58 \pm 0.06$ & $0.27 \pm 0.02$ & $0.23 \pm 0.02$ \\
\hline G17 & $0.25 \pm 0.02$ & $0.32 \pm 0.03$ & $0.79 \pm 0.09$ & $0.2 \pm 0.009$ & $0.80 \pm 0.09$ & $0.65 \pm 0.08$ \\
\hline G18 & $0.35 \pm 0.03$ & $0.47 \pm 0.05$ & $0.84 \pm 0.16$ & $0.14 \pm 0.009$ & $0.07 \pm 0.001$ & $1.60 \pm 0.11$ \\
\hline Min & $0.1 \pm 0.002$ & $0.12 \pm 0.005$ & $0.31 \pm 0.03$ & $0.05 \pm 0.002$ & $0.05 \pm 0.001$ & $0.08 \pm 0.003$ \\
\hline Max & $0.58 \pm 0.06$ & $0.79 \pm 0.09$ & $2.3 \pm 0.22$ & $0.74 \pm 0.09$ & $1.2 \pm 0.09$ & $1.60 \pm 0.11$ \\
\hline Mean & $0.37 \pm 0.04$ & $0.47 \pm 0.05$ & $1.37 \pm 0.16$ & $0.46 \pm 0.05$ & $0.44 \pm 0.04$ & $0.54 \pm 0.06$ \\
\hline
\end{tabular}

which $\mathrm{I}_{\alpha}=1$. The mean computed $\mathrm{I}_{\alpha}$ values for the studied gypsum samples are given in Table 7 for the different gypsum samples. The values of $\mathrm{I}_{\alpha}$ of gypsum samples are values varied in the range between $0.05 \pm 0.002$ to $0.74 \pm 0.09\left(\mathrm{~Bq} \cdot \mathrm{kg}^{-1}\right)$ with mean $0.46\left(\mathrm{~Bq} \cdot \mathrm{kg}^{-1}\right)$. For the safe use of a material in the construction of dwellings, $\mathrm{I}_{\alpha}$ should be less than unity. The mean calculated values were less than unity.

\section{4) eTh/eU, eU/eRa Elemental Ratio}

The eTh/eU ratio has also proven to be useful in the recognition of "geochemical facies". Based on their analyses of numerous rock samples, Adams and Weaver [34], in a classic paper, demonstrated the usefulness of the thoriumto-uranium ratio as an indication of relatively oxidizing or reducing conditions. Uranium has an insoluble tetravalent state that is fixed under reducing conditions, but is transformed to the soluble hexavalent state which may be mobilized into solution. In contrast, thorium has a single insoluble tetravalent state which is geochemically associated with uranium and, therefore, is a useful standard for comparison purposes [35,36].
Adams and Weaver [34] further suggested that ratios <2 were highly suggestive of relative uranium enrichment, and implicates reducing conditions, as contrasted with ratios $>7$, which indicate preferential removal of uranium, possibly by leaching.

A study of the $\mathrm{Th} / \mathrm{U}, \mathrm{K} / \mathrm{U}$ and $\mathrm{K} / \mathrm{Th}$ elemental ratios may provide an indication whether relative depletion or enrichment of radioisotopes had occurred. The theoretically expected $\mathrm{Th} / \mathrm{U}$ elemental ratio for normal continental crust is about 3.0, while the corresponding values obtained for this (min, max, mean) eTh/eU ratio are 0.05 $\pm 0.001,1.2 \pm 0.09$ and 0.44 for gypsum samples respectively, which are more less than the expected value.

The equilibrium factor, which was defined by Hussein [37] as P-factor and expressed in the ratio between radiometrically measured equivalent uranium and equivalent radium (eU/eRa) was calculated in all rock and soil samples. This factor is more or less than unity indicating a state of disequilibrium, while P-equal unity indicated the state of equilibrium. From the estimated values, Table 7 we note that the gypsum samples (G1, G2, G7, G10, G11, 
G12, G13, G14, G17 and G18) are in the equilibrium state within experimental error. Furthermore, the average of the radioactivity hazard indices and radium equivalent values are little more than restricted levels to the public. So, some precautions and recommendations should be followed and consider for the public uses these materials while there are disequilibrium between ${ }^{226} \mathrm{Ra}$ and ${ }^{238} \mathrm{U}$ (eU/eRa) in some gypsum samples (G3, G4, G5, G6, G8, G9, G15 and G16).

\section{CONCLUSIONS}

Exploitation of high-resolution $\gamma$-ray spectroscopy provides a sensitive experimental tool in studying natural radioactivity and determining elemental concentrations and dose rates for various rock types. Eighteen kinds of gypsum were collected from natural and manufactured building materials used in Egypt, considered as the most popular ones, and were measured for their natural radioactivity in order to assess the radiological impact when they are used as building materials. The activities of ${ }^{238} \mathrm{U},{ }^{226} \mathrm{Ra},{ }^{232} \mathrm{Th}$ and ${ }^{40} \mathrm{~K}$ of most the gypsum samples exceed the average level of these radionuclides in regular soil $35 \mathrm{~Bq} \cdot \mathrm{kg}^{-1}$, $35 \mathrm{~Bq} \cdot \mathrm{kg}^{-1}$, $30 \mathrm{~Bq} \cdot \mathrm{kg}^{-1}$ and $400 \mathrm{~Bq} \cdot \mathrm{kg}^{-1}$, respectively. The corresponding absorbed dose rate from all those radionuclides also exceeds significantly the average value of $55 \mathrm{nGy} \cdot \mathrm{h}^{-1}$ from these terrestrial radionuclides in regular soil, and the annual effective dose is based on the standard room model, less than the dose limit of $1 \mathrm{mSv} \cdot \mathrm{y}^{-1}$ for all samples under studies.

In addition, according to the dose criteria recommended by the European Union (EC, 1999), two of the samples meet the exemption dose limit of $0.3 \mathrm{mSv} \cdot \mathrm{y}^{-1}$, "G1, G2", three of them- "G11, G17 and G18" meet the upper dose limit of $1 \mathrm{mSv} \cdot \mathrm{y}^{-1}$, and 13 samples clearly exceed this limit.

The extracted values are, in general, comparable to the corresponding ones obtained from other studies in Egypt, and they all fall within the average worldwide ranges. The results can be considered as basic values for distribution of natural radionuclides in the area and will be used as reference information for determining any future changes.

\section{REFERENCES}

[1] Gypsum Association (2002) Annual gypsum board shipments \& industry capacity. Gypsum Association, Washington DC.

[2] Mineral Information Institute (2001) Look around... Everything is made from something. Mineral Information Institute Poster, Denver.

[3] European Commission (1999) Radiological protection principles concerning the natural radioactivity of building materials. Radiation Protection Report RP-112, European
Commission, Luxembourg.

[4] El-Taher, A. (2010) Gamma spectroscopic analysis and associated radiation hazards of building materials used in Egypt. Radiation Protection Dosimetry, 138, 158-165. http://dx.doi.org/10.1093/rpd/ncp205

[5] Jeambrun, M., Pourcelot, L., Mercat, C., Boulet, B. and Loyen, J. (2012) Study on transfers of uranium, thorium and decay products from grain, water and soil to chicken meat and egg contents. Journal of Environmental Monitoring, 14, 2170-2180.

http://dx.doi.org/10.1039/c2em10994h

[6] Jönsson, M. (2010) Collimation technique for HPGedetector gamma spectrometry in intense radiation fields, Master of Science Thesis, Clinical Sciences, Lund University, Lund.

[7] Ebaid, Y.Y. (2010) Use of gamma-ray spectrometry for uranium isotopic analysis in environmental samples. Romanian Journal, 55, 69-74.

[8] Amrani, D. and Tahtat, M. (2001) Natural radioactivity in Algerian building materials. Applied Radiation and Isotopes, 54, 687-689.

http://dx.doi.org/10.1016/S0969-8043(00)00304-3

[9] Erdtmann, G. and Soyka, W. (1979) The gamma of the radionuclide: Tables for applied gamma ray spectrometry. Verlag Chemic, New York.

[10] Langmuir, D. (1978) Uranium deposits, mineralogy and origin. University of Toronto Press, Toronto.

[11] Mustonen, R., Pennanen, M., Annanmäki, M. and Oksanen, E. (1999) Enhanced radioactivity of building materials. Final Report of the Contract No 96-ET-003 for the European Commission, Radiation and Nuclear Safety Authority, (STUK), Finland.

[12] Mollah, A.S., et al. (1996) The natural radioactivity of some building materials used in Bangladesh. Health Physics, 50, 849-851.

[13] International Atomic Energy Vienna (IAEA) (1994) Calibration of dosimeters used in radio therapy. Technical Reports Series No. 374.

[14] Turhan, S. (2008) Assessment of the natural radioactivity and radiological hazards in Turkish cement and its raw materials. Journal of Environmental Radioactivity, 99, 404-414.

[15] Nour, K. (2005) Measurements of natural radioactivity in building materials in Qena City, Upper Egypt. Journal of Environmental Radioactivity, 83, 91-99. http://dx.doi.org/10.1016/j.jenvrad.2005.03.002

[16] Stoop, P., et al. (1998) Results of the second dutch national survey on radon in dwellings. RIVM, Bilthoven, Report 610058006.

[17] Yu, K.N., et al. (1992) Indoor radon and environmental gamma radiation in Hong Kong. Radiation Protection Dosimetry, 40, 259-263.

[18] Roelofs, L.M.M. and Scholten, L.C. (1994) The effect of aging, humidity, and fly-ash additive on the radon exhalation from concrete. Health Physics, 67, 266. http://dx.doi.org/10.1097/00004032-199409000-00007

[19] Stranden, E., Kolstad, A.K. and Lind, B. (1984) The In- 
fluence of moisture and temperature on radon exhalation. Radiation Protection Dosimetry, 7, 55-58.

[20] Kovler, K., et al. (2005) Radon exhalation of cementitious materials made with coal fly ash: Part 1 -Scientific background and testing of the cement and fly ash emanation. Journal of Environmental Radioactivity, 82, 321. http://dx.doi.org/10.1016/j.jenvrad.2005.02.004

[21] Beck, H.L., De Campo, J. and Gogolak, C. (1972) In situ $\mathrm{Ge}(\mathrm{Li})$ and $\mathrm{NaI}(\mathrm{Tl})$ gamma-ray spectrometry, HASL-258. Environmental Measurements Laboratory, US Department of Energy (DOE), New York. http://dx.doi.org/10.2172/4599415

[22] Yu, K.N., Guan, Z.J., Stokes, M.J. and Young, E.C.M. (1992) The assessment of the natural radiation dose committed to the Hong Kong people. Journal of Environmental Radioactivity, 17, 31-48. http://dx.doi.org/10.1016/0265-931X(92)90033-P

[23] United Nations Scientific Committee on the Effects of Atomic Radiation (2000) Sources and effects of ion-izing radiations. 2000 Report to the General Assembly with Annex B: Exposures from Natural Sources of Radiation, UNSCEAR, New York.

[24] Colgan, P.A., Organo, C., Hone, C. and Fenton, D. (2008) Radiation doses received by the Irish population. Radiological Protection Institute of Ireland, Dublin.

[25] Baykara, O., Karatepe, S. and Doğru, M. (2011) Assessments of natural radioactivity and radiological hazards in construction materials used in Elazig, Turkey. Radiation Measurements, 46, 153-158. http://dx.doi.org/10.1016/j.radmeas.2010.08.010

[26] Rizzo, S., Brai, M., Basile, S., Bellia, S. and Hauser, S. (2001) Gamma activity and geochemical features of building materials: Estimation of gamma dose rate and indoor radoon levels in Sicily. Applied Radiation and Isotopes, 55, 259-265. http://dx.doi.org/10.1016/S0969-8043(00)00384-5

[27] Hayumbu, P., Zaman, M.B., Luhaba, N.C.H., Munsanje, S.S. and Nuleya, D. (1995) Natural radioactivity in Zambian building materials collected from Lusaka. Journal of Radioanalytical and Nuclear Chemistry, 199, 229-238. http://dx.doi.org/10.1007/BF02162371
[28] ICRP (1991) Annals of the ICRP, 1990. Recommendations of the International Commission on Radiological Protection, ICRP Publication 60, Pergamon Press, Oxford.

[29] Beretka, J. and Mathew, P.J. (1985) Natural radioactivity of Australian building materials, industrial wastes and byproducts. Health Physics, 48, 87-95. http://dx.doi.org/10.1097/00004032-198501000-00007

[30] European Commission (EC) (1999) Radiation protection 112. Radiological Protection Principles Concerning the Natural Radioactivity of Building Materials, DirectorateGeneral Environment, Nuclear Safety and Civil Protection.

[31] ICRP (1994) Protection against Rn-222 at home and at work. Publication No. 65, Annals of the ICRP, 23, Pergamon, Oxford.

[32] Khan, K., Aslam, M., Orfi, S.D. and Han, H.M. (2002) Norm and associated radiation hazards in bricks fabricated in various locations of the North-West Frontier Province (Pakistan). Journal of Environmental Radioactivity, 58, 59-66. http://dx.doi.org/10.1016/S0265-931X(01)00030-3

[33] Komura, K. (1997) Challenge to detection limit of environmental radioactivity. Proceedings of the International Symposium on Environmental Radiation, Tsuruga, Fukui, 20 October 1997, 56-75.

[34] Adams, J.A.S. and Weaver, C.E. (1958) Thorium to uranium ratios as indications of sedimentary processes: Example of concept of geochemical facies. American Association of Petroleum Geologists Bulletin, 42, 387-430.

[35] Macfarlane, P.A., Whittemore, D.O., Townsend, M.A., Doventon, J.H., Hamilton, V.J., Coyle III, W.G., Wade, A., Macpherson, G.L. and Black, R.D. (1989) The Dakota aquifer program annual report, FY89. Appendix B. Kansas Geological Survey, Open-File Report 90-27.

[36] Doventon, J.H. and Prensky, S.E. (1992) Geological applications of wireline logs: A synopsis of developments and trends. Log Analyst, 33, 286-303.

[37] Hussein, A.H., Abdel Monem, A.A., Mahdy, M.A., ElAassy, I.E. and Dabbour, G.M. (1992) On the genesis of surficial uranium occurrences in west central Sinai, Egypt. Ore Geology Reviews, 7, 125-134. 